\title{
Research on the protection and renewal of industrial heritage in Wuhan against the backdrop of rapid urbanization
}

\author{
Hong $\mathrm{Xu}^{1,2, \mathrm{a}}$, Yan Long ${ }^{1,2, \mathrm{~b}}$ \\ ${ }^{1}$ College of Urban Construction, Wuhan University of Science and Technology, China \\ ${ }^{2}$ Institute of Smart City and Intelligent Urban-rural development,Wuhan University of Science and \\ Technology, China \\ a1010xh@163.com, ${ }^{\mathrm{b}}$ 3775574@qq.com
}

\begin{abstract}
Keywords: industrial heritage;protection;renewal;rapid urbanization
Abstract. This paper analyzes the development and present situation of industrial heritage in Wuhan, and sums up the methods of renovation and renewal of industrial heritage in Wuhan. The prospects for the development of industrial heritage conservation are also prospected, and suggestions for the protection and renewal of industrial heritage are put forward.
\end{abstract}

\section{Introduction}

China is now in a special historical period from the industrialized society to the backward industrialized society. At the same time, China is now in a stage of rapid urbanization. The rapid development of urbanization has brought about the rapid expansion of urban scale.In the process of rapid urban expansion, the expansion of urban scale requires more urban construction land, while the city itself is limited in land resources, which makes the development of the city must face the problem of urban renewal.In the urban renewal, due to the upgrading and transformation of the industrial structure, a large number of old industrial areas and old factories in the city have been abandoned and idled, which makes it become one of the primary goals of urban renewal.Under the pressure of city renewal, in the old industrial area of the city and the old factory, a large number of old industrial buildings and old industrial area in the overall environment have been destroyed, including a large number of valuable industrial heritage is destroyed.Therefore, how to make reasonable protection and effective utilization of industrial heritage under the background of urban renewal has become an important problem in the urban development of our country.

Hubei is the birthplace of Chinese in modern industry, an important gathering area is China modern manufacturing industry, as early as in the national industry, developed during the Westernization Movement period, reconstruction of the former Soviet Union Chinese period, three line construction period, here left a large number of industrial heritage.Wuhan is one of the most influential industrial bases throughout the country. After the Qing Dynasty Westernization Movement, the period of the Republic of China national industry development, the new Chinese over the years of construction, Wuhan has become the epitome of China industrialization development, the distinctive traces for the modernization of Chinese.

\section{The development and present situation of industrial heritage in Wuhan}

The development of industrial heritage in Wuhan should contain three periods:One is Zhang Zhidong's governing period, established a series of modern industrial enterprises, such as the cultural relics of Hanyang iron factory, Hanyang Arsenal and Wuchang "silk and hemp gauze four Bureau and a number of factories left. In the period of the Republic of China, the industry of Wuhan have great development to the eve of war, Qingdao, Shanghai and Wuhan which together became the most important textile industry base China ${ }^{[1]}$. The prosperity of these factories and enterprises laid a solid industrial foundation for Wuhan. after the founding of the people's Republic of China, Wuhan became an important industrial base for national investment. At the beginning of the founding of the people's Republic of China, 7 of the 156 key construction projects designated by the state were settled in Wuhan.High technology promotes the rapid development of economy and keeps old industries out. A 
few years, many old enterprises, large enterprises site was quietly replaced by new buildings and blocks.

Now many of Wuhan's industrial heritage is gone. Many have become commercial streets and residential areas. For example, Hubei construction machinery factory disappeared, replaced by the "Jingxiu Jiangnan" business district; Hubei motor factory, Wuhan air blower factory, Wuhan sewing machine factory and Wuhan micro motor factory Wuhan auto parts factory, bearing factory and other enterprises have also been the site of all gone.

\section{Methods and examples of industrial heritage transformation in Wuhan}

The protection and renewal of industrial heritage has always been a difficult problem for us. Although the industrial heritage of Wuhan is almost gone, there are also some designs that have been updated and transformed according to the historical value. there are also some ways and means to use it in the process of transformation and utilization. Generally speaking, it can be summed up as follows.

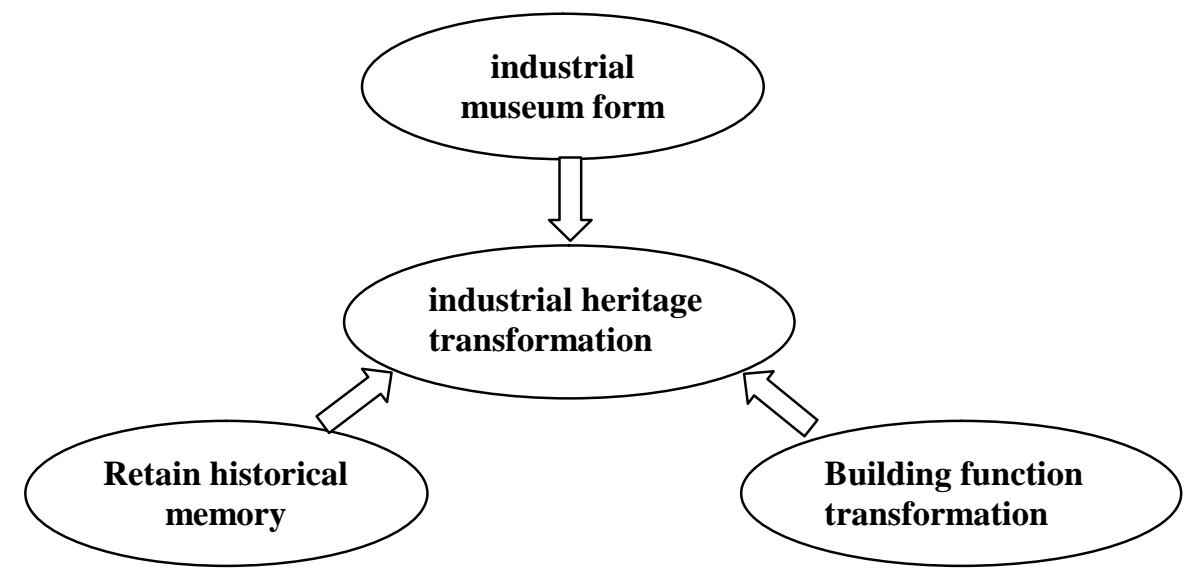

Figure .1 industrial heritage transformation model

(1)Retain historical memory

Although the industrial heritage has faded away in years, the memories that remain in the minds of one generation can not be erased. Many industrial estates have now become real estate development projects, but some architectural symbols and some architectural spaces are often preserved.

Wuhan heavy machine tool plant, in 1953 preparation, officially put into operation in 1958, when a Soviet style gate, opened the heavy military brilliant journey. Junior $\mathrm{Wu}$ heavy, was marked with heavy "Soviet" brand. Including the gate, the design and construction of the heavy workshop was basically completed by the Soviet union.With the rapid development of urbanization, in order to cope with the "two oriented society" transformation, and do a good job of ecological construction of large East Lake water network project, the overall relocation of $\mathrm{Wu}$, Wuhan, East Lake New Technology Development Zone, Wu heavy community is also included in the scope of demolition. In the face of the demolition of the heavy weights factory, under the appeal of a batch of old workers and people of social insight, the old heavy gate as a symbol must be retained ${ }^{[2]}$. The ground or the piece of land, just a row of high-grade residential buildings, flooded the old buildings. The old gate survived, with vermilion writing "heavy", appears to be a reason for it by leaving memories. The old gate, Wuhan heavy machine tool plant door has become a symbolic arch.

(2)Industrial Museum form

Through the form of the museum to showcase some of the production process, from the activation in the industrial historical area and real sense, and stimulate community participation and sense of identity, also can be used as artistic creation base, to carry out some works of art exhibition. 
In 2005, approved by the Wuhan municipal government, in full support of WISCO, Wuhan Hanyang mills built a large-scale "Zhang Zhidong and Hanyang ironworks Museum", attracted a large number of tourists to visit. This is a symbol of Wuhan's attention to industrial heritage protection. The hall of the building area is more than 300 square meters. It concludes the exhibition Hanyang ironworks, Arsenal and Zhang Zhidong and other relics relics of more than 100. It is a true reflection of the difficult course of history that Hanyang iron works and national iron and steel industry development in china.

Wuhan Iron and steel museum(WISCO Museum) is an important base for the protection of the industrial and technological heritage of the iron and steel industry in our city. The museum is not just limited to the transformation of the Wuhan theatre, may also include Wuhan City Qingshan District of metallurgical industry characteristics of Soviet style architecture (for area protection and overall renovation, but as red Frank eight neighborhood staff dormitory area).

(3)Building function transformation

In the former site of the industry or old building to build some public participation in recreational facilities, as a place for people to leisure and entertainment.

Wuhan boiler factory is one of the earliest large-scale state-owned enterprises in china.Now carrying the memories of the old generations of Wuhan boiler factory located into a large residential area, the old beam in the roar, the blue frock is all gone. In the former industrial sites, today's culture is the new site 403 International Art Center after the design planning designer, double space within 3000 meters of the segmentation of four cultural and creative pioneer plate: Wandering bookstore, red chair theatre, the art of white space, the prototype creative entrepreneur. although the center front decoration glass curtain wall, but the shape of the original workshop is visible, walked into the door, from the center of open atrium space can be seen at the top of the workshop. The space combination changeable contains rich formats, breaking professional boundaries through space integration, the 403 International Art Center to create a "cross" as the core value of "internationalization" as the benchmark brand, culture complex with innovative creation of "New Youth" spirit as the core.

\section{Conclusions}

With the deepening of the understanding of the history of urban renewal, a large number of structural waste of the old city industrial buildings have been turned to new construction and the use of old. In the process of rapid urbanization, in the process of declining and renewing of traditional manufacturing industry, some production sites and factories become an important heritage to record the process of urban industrialization.The protection and reuse of industrial heritage is the need of sustainable development of the city, but also an important way to extend the vitality of the city, is a kind of respect to the industrialization era of civilization and continuation of social history, it is a kind of human material wealth and spiritual wealth.There are some suggestions in the industrial heritage conservation and renovation in the future:

(1)The concept of protection should be strengthened

The importance of industrial heritage has not been paid due attention to, and cultural values have often been neglected. Many important factories have been dismantled and historical memories have been removed.Therefore, from the government to the public, the concept and consciousness of protection should be further promoted, infiltrated and strengthened.

(2)Making historical value evaluation criteria

The historical value of industrial architectural heritage includes many aspects. The historical value, technical value, social value, aesthetic value, economic value, authenticity and integrity of the industrial heritage are evaluated. Through the comparison and demonstration of multiple plans, the evaluation index hierarchy diagram is established.

(3)Respecting history and protecting environment

Now Carrying out industrial heritage tourism, developing public leisure space and building characteristic parks of industrial heritage are the main ways of utilizing industrial heritag $\mathrm{e}^{[3]}$. We must 
respect the original historical features while developing and utilizing it. At the same time, we should pay attention to the surrounding environment.

(4)Insisting on sustainable development

The sustainable utilization of industrial heritage meets the dual needs of energy conservation, environmental protection and historical heritage of urban regeneration. In the premise of outstanding cultural connotation and local characteristics, in order to re-use of industrial heritage as the breakthrough point, as the city revival of key sections of the engine and the means to carry out is one of the main methods of Wuhan industrial heritage protection practice.In the current development needs of ecological environmental protection, industrial and architectural heritage area after the transformation in line with lower energy consumption at the same time, and to meet human comfort requirements, is an important way to realize the sustainable development of the industrial heritage ${ }^{[4]}$.

\section{Acknowledgments}

The research was supported by Excellent Young Teachers Program of Wuhan University of Science and Technology (Grants \#2012XZ020), the Science-Technology Foundation for Young Scientist of Hubei Province, China (Grants \#Q20131101) and Social Science Research Foundation for Young Scientist of Hubei Province, China(Grants \#14Q020).

\section{References}

[1] TianYan: Study on the Conservation and Sustainable Utilization of Industrial Heritage in Wuhan, Chinese Landscape Architecture, 9(2013), p.90-95

[2] Wang Song,Yuan Nuoya:Renewal of Industrial Heritage in Urban Waterfront Areas — The Detailed Planning of Yang Sigang-Harbor Area, Wuhan,Chinese \& Overseas Architecture, 10(2014),P.75-78

[3] Xu Suning,Wang Guoqing,LI Shifen,LI Tao,L Zhenghua,LIU Yan:Industrial Heritage Protection and Urban Regeneration,City Planning Review,Vol. 41, (2017),P.81-84.101

[4] Zeng Rui, Yu Li, Li Zao, Ye Maosheng:Present Situation and Revelation from Protection and Reuse of Foreign Industrial Heritages, Industrial Construction Vol. 46, (2016),P.1-4 